\title{
Erratum to: Energy cost optimization in pressurized irrigation networks
}

\author{
I. Fernández García ${ }^{1}$ P. Montesinos ${ }^{1}$ E. Camacho Poyato ${ }^{1}$ J. A. Rodríguez Díaz ${ }^{1}$
}

Published online: 27 October 2015

(C) Springer-Verlag Berlin Heidelberg 2015

\section{Erratum to: Irrig Sci}

DOI 10.1007/s00271-015-0475-3

A part of Fig. 2 was missing in the original version of this article. The correct version of Fig. 2 is given below with the missing table annexed to it.

The online version of the original article can be found under doi:10.1007/s00271-015-0475-3.

I. Fernández García g52fegai@uco.es

P. Montesinos pmontesinos@uco.es

E. Camacho Poyato ecamacho@uco.es

J. A. Rodríguez Díaz jarodriguez@uco.es

1 Department of Agronomy, University of Cordoba, Campus Rabanales, Edif. Da Vinci, 14071 Córdoba, Spain 
Fig. 2 Flow-Head histogram of the three sectors and monthly crop water requirements (IN)

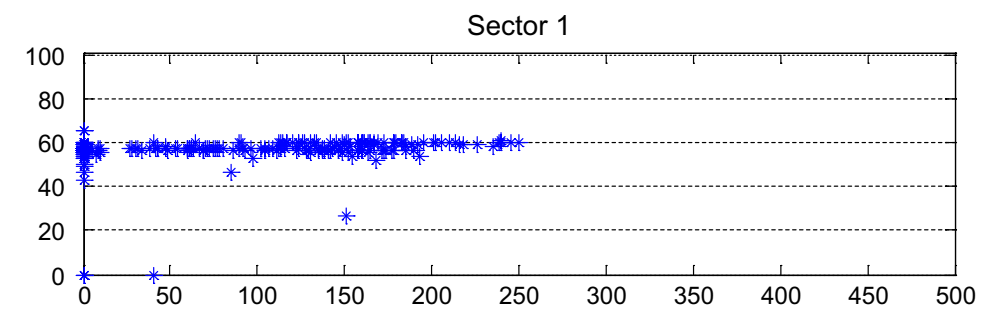

Sector 2

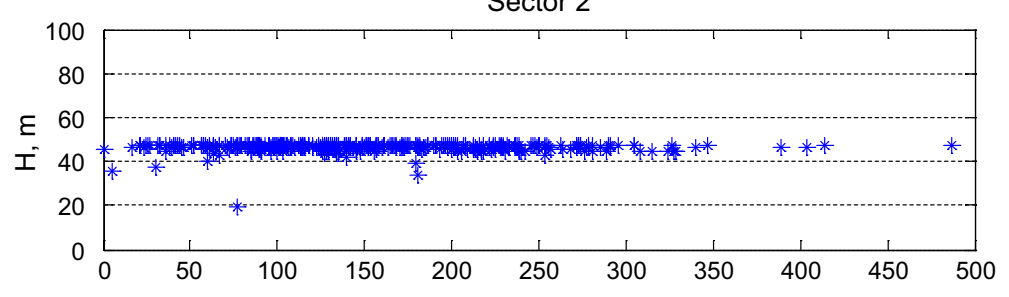

Sector 3

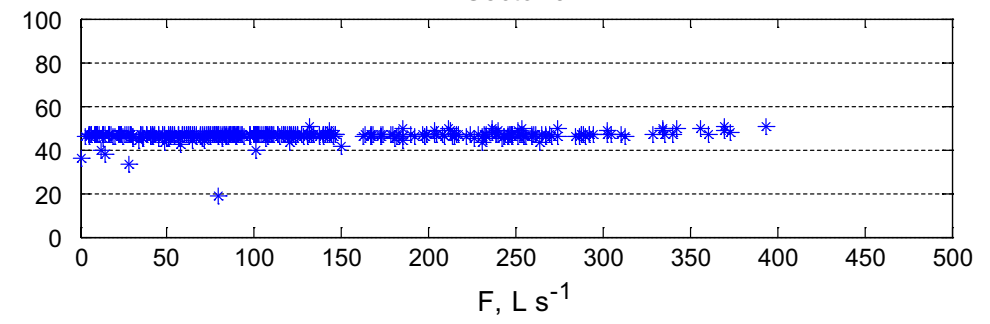

\begin{tabular}{ccccccccccccc}
\hline & Jan & Feb & Mar & Apr & May & Jun & Jul & Aug & Sep & Oct & Nov & Dec \\
\hline $\begin{array}{c}\text { IN } \\
\text { mm day }^{-1}\end{array}$ & 0.7 & 1.1 & 2.1 & 2.9 & 4.1 & 1.5 & 0.9 & 2.0 & 1.7 & 2.0 & 0.9 & 0.7 \\
\hline
\end{tabular}

